\title{
PATIENT ADHERENCE AND SATISFACTION OF A MINDFULNESS-BASED STRESS REDUCTION TREATMENT FOR ANXIETY DISORDERS: PRELIMINARY DATA FROM AN OBSERVATIONAL INVESTIGATION
}

Borghi $\mathrm{S}^{1}$, Crosta $\mathrm{ML}^{1}$, Messina $\mathrm{V}^{2}$, Pozzi G1

${ }^{1}$ Institute of Psychiatry and Psychology, Catholic University of the Sacred Heart

Fondazione Policlinico Universitario Agostino Gemelli IRCCS - Rome (Italy)

${ }^{2}$ LUMSA University - Rome (Italy)

Background. Traditional psychotherapies of Anxiety Disorders (ADs) are effective but are not always sustainable. Jon Kabat-Zinn, through his Mindfulness-Based Stress Reduction protocol (MBSR), expanded the practice of mindfulness within a scientific approach. He originally defined "mindfulness" as the tendency to pay attention "on purpose, in the present moment, and non-judgmentally". Mindfulness-based intervention proved to be particularly flexible and adaptable to different clinical populations, and in particular to ADs.

Anxious subjects show an alteration of their cognitive processes distorting the analysis of the present experience, which is perceived as threatening and distressing. This mode affects the tendency of the individual to focus attention on future concerns, losing sight of the present moment. A short-course MBSR treatment may be a rather inexpensive option for the improvement of clinical symptoms and the functional rehabilitation of patients with $A D$.

Objectives. To evaluate the acceptability of a MBSR intervention among patients seeking treatment for ADs.

Materials and methods. Subjects are adult mid-class patients suffering from Generalized Anxiety Disorder (GAD) evaluated in a tertiary-level outpatient clinic; as necessary, anxiety symptoms were stabilized by means of a drug treatment at ordinary doses (SSRIs, SNRIs, other). Patients are recruited on a free-will base and pay a small fee for participation. A typical MBSR manualized treatment is delivered in small group sessions (6 to 10 people) during a 8-week course by an expert therapist/trainer. The Mindful Attention Awareness Scale (MAAS) is administered at the beginning and at the end of the treatment course, and patients complete a final satisfaction questionnaire in anonymity.

\begin{tabular}{|r|r|}
\hline Subjects: & $\mathbf{1 0}$ \\
\hline Gender: & \\
0 & \\
0 & 7 \\
Age: & 3 \\
\hline Mean \pm SD) & $47 \pm 18,5$ \\
\hline Educational qualification: & 3 \\
University degree & 7 \\
\hline High school diploma & \\
Diagnosis: & 10 \\
\hline Generalized Anxiety Disorder & \\
Ethnicity: & 10 \\
\hline
\end{tabular}

Table 1. Social and demographic characteristics of the clients

\begin{tabular}{|c|c|c|c|}
\hline 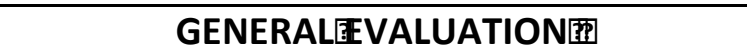 & ?] & ? & ? \\
\hline $\begin{array}{l}\text { In general, the course contents } \\
\text { do they meet your expectations? }\end{array}$ & $\begin{array}{c}\text { ] } \\
\text { Yes[ } \\
\text { 9国90\%)? }\end{array}$ & $\begin{array}{c}\text { ] } \\
\text { Partially? } \\
\text { 1国10\%)? }\end{array}$ & $\begin{array}{c}\text { ] } \\
\text { No? } \\
\text { 0国0\%)] }\end{array}$ \\
\hline $\begin{array}{l}\text { How do you judge the duration of the course } \\
\text { compared to the contents? }\end{array}$ & $\begin{array}{c}\text { ] } \\
\text { Inadequate回 } \\
\text { 1国10\%)? }\end{array}$ & 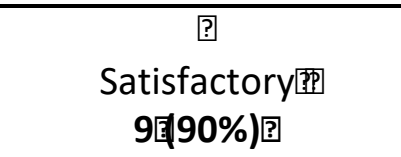 & $\begin{array}{c}\text { ] } \\
\text { Excessive? } \\
\text { 0国0\%)回 }\end{array}$ \\
\hline TEACHING? & ? & 司 & ? \\
\hline $\begin{array}{l}\text { What is your opinion on the effectiveness } \\
\text { of the teaching methods used in the course? }\end{array}$ & $\begin{array}{c}\text { ] } \\
\text { Satisfactory? } \\
\text { 10国100\%)] }\end{array}$ & 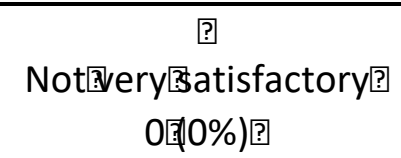 & $\begin{array}{c}\text { Unsatisfactory? } \\
\text { 0国0\%)回 }\end{array}$ \\
\hline How do you rate the teaching material provided? & $\begin{array}{c}\text { ] } \\
\text { Useful] } \\
\text { 10国100\%)? }\end{array}$ & $\begin{array}{c}\text { ] } \\
\text { Not国ery目sefulla } \\
\text { 0国0\%)回 }\end{array}$ & $\begin{array}{c}\text { ] } \\
\text { Useless? } \\
\text { 0国0\%)回 }\end{array}$ \\
\hline How do you rate the interaction with the trainer? & $\begin{array}{c}\text { ] } \\
\text { Satisfactory? } \\
\text { 10国100\%)] }\end{array}$ & $\begin{array}{c}\text { ? } \\
\text { Not国ery活atisfactory? } \\
\text { 0国0\%)回 }\end{array}$ & $\begin{array}{c}\text { Unsatisfactory? } \\
\text { 0[0\%)? }\end{array}$ \\
\hline ORGANIZATION] & ] & 司 & ] \\
\hline $\begin{array}{l}\text { How do you judge the organization } \\
\text { and logistics (accessibility, environment, etc.)? }\end{array}$ & $\begin{array}{c}\text { ] } \\
\text { Satisfactory? } \\
\text { 9国90\%)] }\end{array}$ & $\begin{array}{c}\text { 国 } \\
\text { Not国ery政atisfactory? } \\
\text { 1国10\%)回 }\end{array}$ & 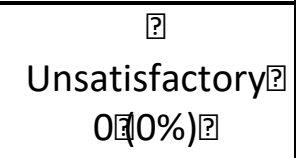 \\
\hline 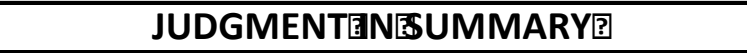 & ?] & ?? & ?? \\
\hline $\begin{array}{l}\text { We invite you to rate with a grade from } 1 \text { to } 4 \\
\text { the overall quality of the course? }\end{array}$ & $\begin{array}{l}\text { 回 } \\
\text { 回 }\end{array}$ & $\begin{array}{c}\text { 回 } \\
\text { 3,8回 }\end{array}$ & ? \\
\hline
\end{tabular}

Table 2. End-of-course satisfaction questionnaire

Results. Ten subjects participated in the MBSR protocol (see Table 1) and were generally satisfied (see Table 2). All patients filled in the MAAS items at the beginning and at the end of the treatment. The scale showed a good reliability (Cronbach's alpha $=0,889$ ). The mean score before starting the treatment was $4,58 \pm 1,34$, while the mean score at the end of the treatment was 5,29 $\pm 0,95$. A nonparametric Wilcoxon test for paired samples was performed, showing that the improvement in the test score is statistically significant $(p=.011)$.

MAAS mean at $\mathrm{T} 1$ and $\mathrm{T} 2$

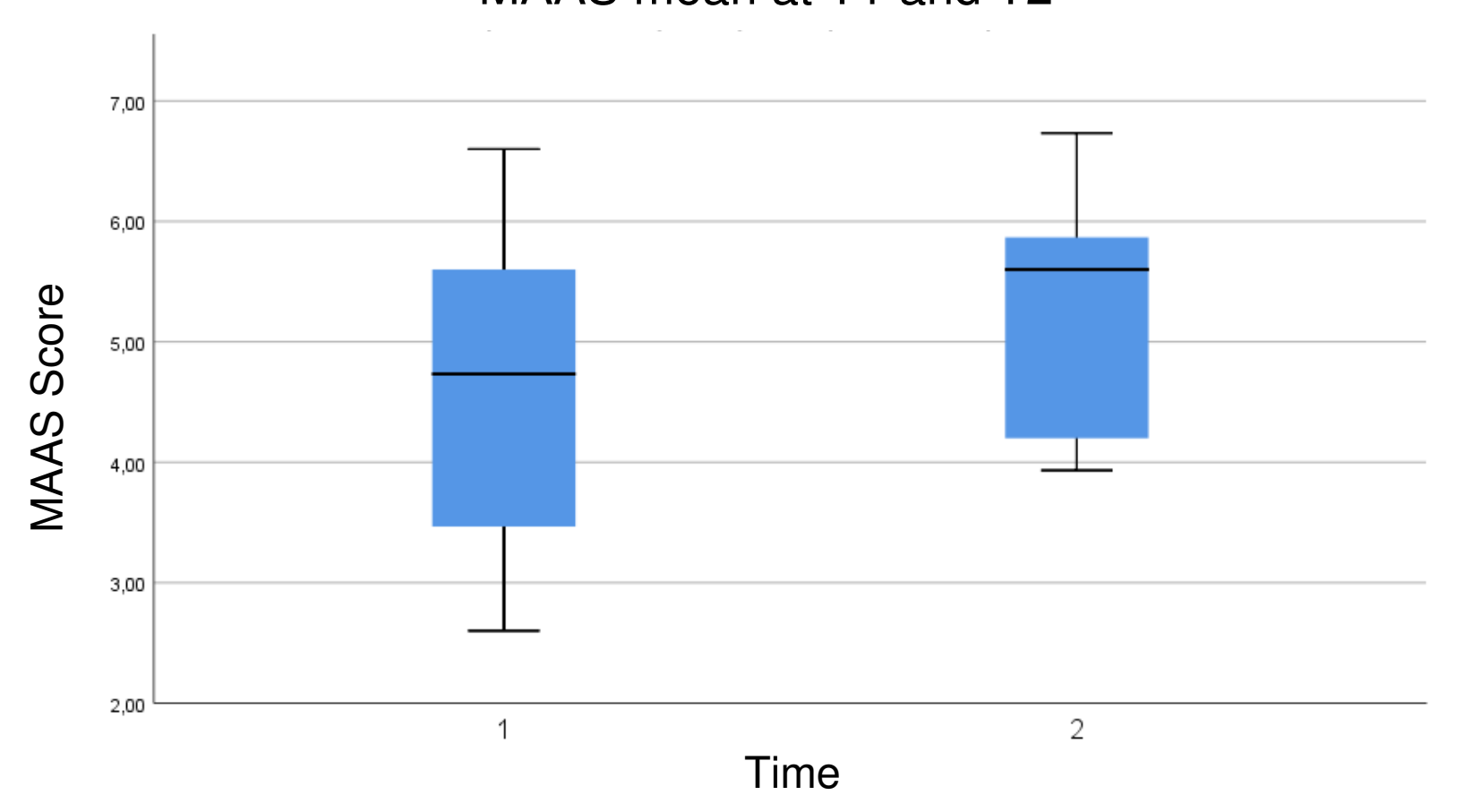

Conclusions. The MBSR treatment works well and patients with anxiety disorders show high levels of adherence. As a rule, treatment is well accepted although some people complain about environmental discomfort due to the specific hospital context. 